San Antonio Review • San Antonio Review (Issue 2 | Winter 2019)

\title{
Sunny Lake Crazy
}

Rex Wilder

Published on: Jul 24, 2019

Updated on: Aug 03, 2020

License: Creative Commons Attribution 4.0 International License (CC-BY 4.0). 
The absent-minded

Looks sheeting the nurses'

Faces are blasphemous

Here at sunny Lake Crazy.

I am condescended to

Like a walking diaper

At best, except it's my head

That's incontinent.

This woman, if I flirt

With her now, it'd

Be like the old man

In the wheelchair

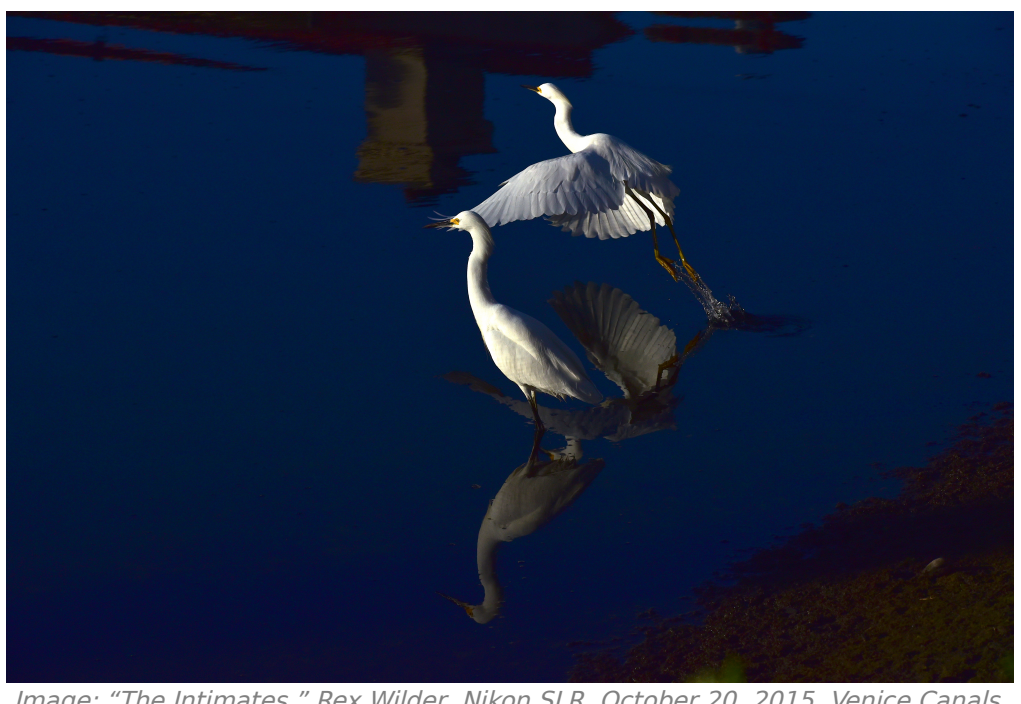

Who pinches the nurse's

Ass. For all I know

I'm limp all over.

She'd slap my wrist

While looking

At her watch \& enter

The incident in her log.

I can't even get

A pity face this morning.

Not even from

The man in the mirror.

Rex Wilder has published poetry in Poetry (Chicago), TLS (London), The Nation, The National Review, The New Republic, Yale Review, Harvard Review, Antioch Review, Ploughshares and many anthologies. Rex has published four books.

Image: "The Intimates," Rex Wilder, Nikon SLR, October 20, 2015, Venice Canals. This photo, among others, will be included in an upcoming volume from Chatwin Books in Seattle which features many images of the beautiful flora, fauna and bridges of this historical urban oasis. 